\title{
Hearing Impairment Increases Economic Inequality
}

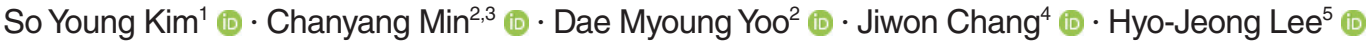 \\ Bumjung Park ${ }^{5}$ (iD $\cdot$ Hyo Geun $\mathrm{Choi}^{2,5}$ (i) \\ ${ }^{1}$ Department of Otorhinolaryngology-Head and Neck Surgery, CHA Bundang Medical Center, CHA University, Seongnam; ${ }^{2} H a l l y m$ Data Science \\ Laboratory, Hallym University College of Medicine, Anyang; ${ }^{3}$ Graduate School of Public Health, Seoul National University, Seoul; \\ ${ }^{4}$ Department of Otorhinolaryngology-Head and Neck Surgery, Hallym University Medical Center, Hallym University College of Medicine, Seoul; \\ ${ }^{5}$ Department of Otorhinolaryngology-Head and Neck Surgery, Hallym University Sacred Heart Hospital, Hallym University College of Medicine,
}

Anyang, Korea

Objectives. We evaluated changes in income levels in a hearing-impaired population.

Methods. The study subjects were selected from the Korean National Health Insurance Service-Health Screening Cohort data from 2002 to 2015 of Koreans $\geq 40$ years old. In total, 5,857 hearing-impaired subjects were matched with 23,428 comparison participants. Differences between the initial income level and income levels at 1, 2, 3, 4, and 5 years post-enrollment were compared between the hearing-impaired and comparison groups. The interaction of time and hearing impairment/comparison was estimated.

Results. Both the hearing-impaired group and the comparison group showed increased income levels over time. In the hearing-impaired group, the income levels at 4 and 5 years post-enrollment were higher than the initial income level (each $P<0.001$ ). In the comparison group, the income levels of all the participants after 1-5 years were higher than the initial income level (each $P<0.001$ ). The interaction of time and hearing impairment was statistically significant $(P=0.021)$.

Conclusion. The increase in income over time was relatively lower in the hearing-impaired adult population; therefore, the income gap widened between this population and the normal-hearing population.

Keywords: Hearing Loss; Economic Status; Income; Cohort Studies

\section{INTRODUCTION}

Advances in medicine have reduced mortality from life-threatening diseases [1]. However, the morbidity and economic burdens of chronic diseases have received attention due to extended life expectancy and the corresponding increase in the incidence of age-related diseases, such as age-related hearing impairment [2]. Hearing impairment is one of the most common sensory or-

\footnotetext{
- Received February 16, 2021

Revised March 16, 2021

Accepted March 27, 2021

- Corresponding author: Hyo Geun Choi

Department of Otorhinolaryngology-Head and Neck Surgery, Hallym

University Sacred Heart Hospital, 22 Gwanpyeong-ro 170beon-gil,

Dongan-gu, Anyang 14068, Korea

Tel: +82-31-380-3849, Fax: 82-31-386-3860

E-mail: pupen@naver.com
}

gan disorders. It has been estimated that approximately $23 \%$ of the 12-year-old or older population in the United States suffers from hearing impairment [3]. The prevalence of hearing impairment increases with age, and approximately $81.4 \%(8,625,367 /$ $10,600,197)$ of the 80 -year-old or older population has hearing impairment [4]. The prevalence of hearing impairment in the aged population was projected to double between 2011 and 2016 [5], and age-related hearing impairment was ranked as the third most burdensome disease in 2016 [6]. Hearing impairment has adverse effects on daily activities, including communication difficulties and social isolation [7]. These problems in hearing-impaired populations may result in a substantial socioeconomic burden $[5,6]$.

A number of previous studies have identified socioeconomic disparities in hearing-impaired populations [8]. These socioeconomic inequalities, which have been measured by disability-ad-

Copyright (C) 2021 by Korean Society of Otorhinolaryngology-Head and Neck Surgery.

This is an open-access article distributed under the terms of the Creative Commons Attribution Non-Commercial License (https://creativecommons.org/licenses/by-nc/4.0)

which permits unrestricted non-commercial use, distribution, and reproduction in any medium, provided the original work is properly cited. 
justed life years, the Gini coefficient, and the concentration index in hearing-impaired populations, were estimated to be stable from 2005 to 2010 and increased slightly from 2010 to 2015 in a survey of 184 countries [8]. Conflicting results have been reported on the association of hearing impairment with low education and income levels. The National Health and Nutrition Examination Survey in the United States reported that hearing impairment was associated with a lower education level (odds ratio [OR], 3.21; 95\% confidence interval [CI], 2.20-4.68), lower income level (OR, 1.58; 95\% CI, 1.16-2.15), and decreased employment (OR, 1.98; 95\% CI, 1.38-2.85) [9]. In South Korea (hereafter, Korea), individuals with a low income level showed 1.97-fold higher odds for hearing impairment ( $95 \%$ CI, 1.40 2.55) than their counterparts [10], although another study found no relationship between hearing impairment and lower income when participants were matched by education level [11]. However, most previous studies did not match hearing-impaired individuals with a comparison population for demographic factors or adjust for comorbidities. In addition, no prior studies have evaluated changes in income over time by tracking the participants.

If hearing impairment affects patients' economic status, it would be important for policymakers and clinicians to estimate the magnitude of the effect and to support patients accordingly. Our hypothesis was that hearing impairment could impact income, there by increasing the economic gap between hearing-impaired and normal-hearing groups. To test this hypothesis, changes in the income levels of hearing-impaired and matched comparison participants were followed annually. The initial income level and demographic factors were matched between the hearing-impaired and comparison groups. Moreover, lifestyle factors and other comorbidities were adjusted when comparing these differences.

\section{MATERIALS AND METHODS}

\section{Study population}

The Ethics Committee of Hallym university (2019-10-023) approved this study. The requirement for written informed consent was waived by the institutional review board of Hallym university.The Korean National Health Insurance Service-Health Screen-

\section{H I G H L I G H T T S}

- Changes in the income level of hearing-impaired and matched comparison participants were followed annually.

- The increase in income level was lower in the hearing-impaired group than in the comparison group.

- Although both the hearing-impaired and comparison groups demonstrated increased income levels, the economic inequality in the hearing-impaired population increased over time. ing Cohort (NHIS-HEALS) data are described in a previous study [12].

\section{Definition of hearing impairment}

Hearing impairment was an exposure in the present study. The hearing-impaired group was defined as the registered hearingimpaired persons in the Ministry of Health andWelfare of Korea following our previous studies $[13,14]$. All the hearing-impaired persons were tested three times using pure-tone audiometry (PTA) and once with an auditory brainstem response threshold test. Based on the 6-tone average of air conduction PTA $([500 \mathrm{~Hz}+2 \times$ $1,000 \mathrm{~Hz}+2 \times 2,000 \mathrm{~Hz}+4,000 \mathrm{~Hz}] / 6)$, individuals with hearing threshold $\geq 60 \mathrm{~dB}$ in both ears or $\geq 80 \mathrm{~dB}$ in one ear and $\geq 40 \mathrm{~dB}$ in the other ear are registered as hearing impaired. Registered hearing impairments are further classified as profound hearing loss for a hearing threshold $\geq 90 \mathrm{~dB}$ in both ears and severe hearing loss for the rest.

\section{Definition of income level}

Income level was an outcome in the present study. Income level was divided into population deciles based on the Korea National Health Insurance premium every year from 1 (the lowest 10\%) to 10 (the highest $10 \%$ ) for the entire Korean population with health insurance. In addition, medical aid beneficiaries were added to the lowest income level (0 class) [15]. The change in income level for participants was evaluated based on the most recent income before the index date (initial income) and was followed for 5 years.

\section{Participant selection}

The hearing-impaired group was selected from 514,866 participants from 2002 through $2015(n=6,626)$. Participants were included in the comparison group if they were not registered as hearing-impaired persons during the same period $(n=508,240)$. Subjects were excluded if they were diagnosed with other disabilities (mobility disorder, visual impairment, mental retardation, psychotic disorder, and kidney disorder, $n=79$ and 43,673 in the hearing-impaired group and comparison group, respectively). Hearing-impaired participants after $2011(n=688)$ were not included in the study. Participants with disabilities were excluded from the comparison participants $(n=43,673)$. The hearing-impaired subjects were matched 1:4 with the comparison subjects for age, sex, initial income on the index date, and region of residence. The comparison participants were selected with a random number order. The index date of each hearing-impaired subject was set as the day of registration of hearing impairment. The index date of the comparison participants was set as the same index date as their matched hearing-impaired subject. During this matching procedure, two hearing-impaired and 441,139 comparison subjects were excluded. Ultimately, 5,857 hearingimpaired subjects were matched with 23,428 comparison participants (Fig. 1). 


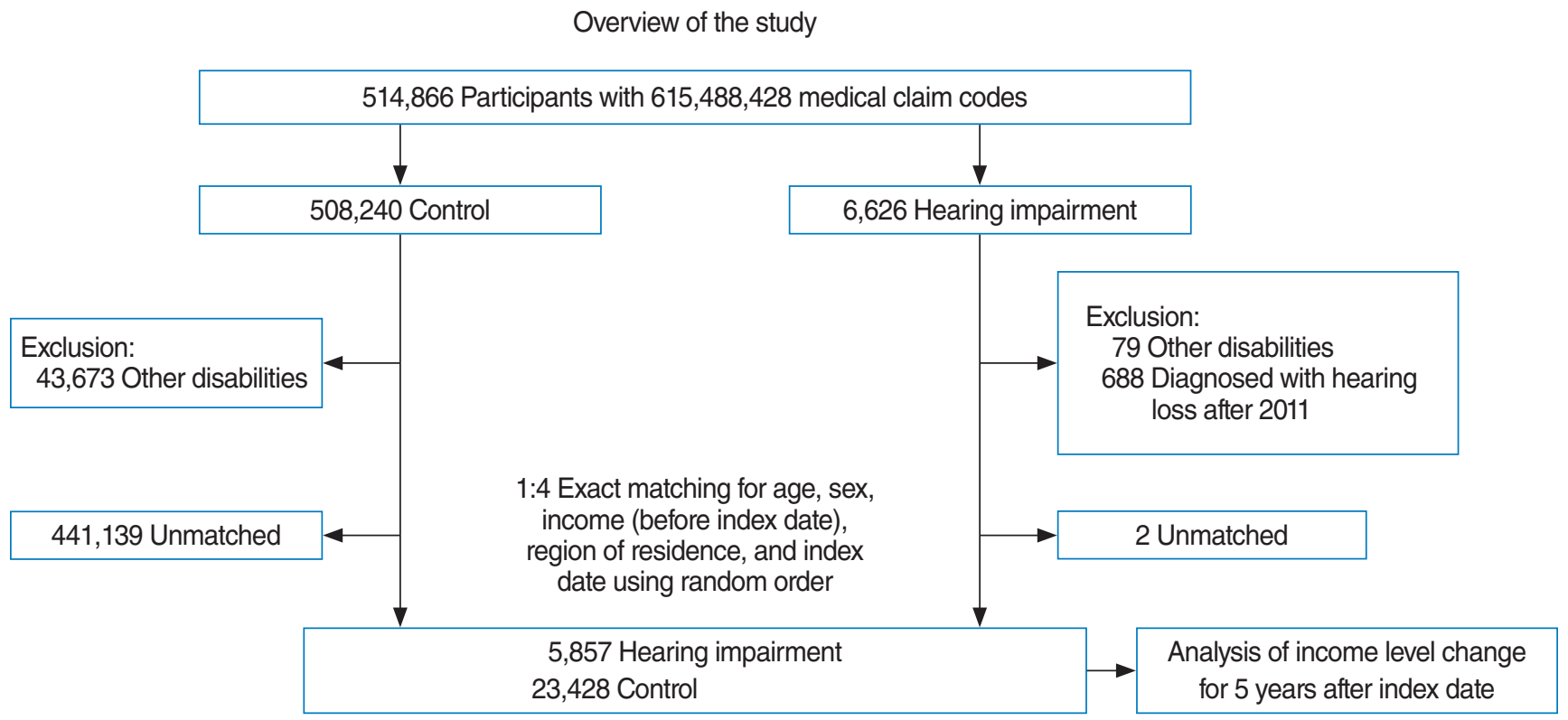

Fig. 1. A schematic illustration of the participant selection process used in the present study.

\section{Covariates}

Ten age groups were identified. The region of residence was divided into urban and rural areas. Tobacco smoking, alcohol consumption, and obesity based on body mass index (BMI $\mathrm{kg} / \mathrm{m}^{2}$ ) were investigated [16]. Systolic blood pressure, diastolic blood pressure, fasting blood glucose, and total cholesterol were included. Missing BMI (28/29,285 [0.096\%]), systolic blood pressure $(16 / 29,285$ [0.055\%]), diastolic blood pressure $(18 / 29,285$ [0.061\%]), fasting blood glucose $(46 / 29,285[0.157 \%])$, and total cholesterol $(65 / 29,285[0.222 \%])$ were replaced by the mean values of each variable from the study population. The Charlson comorbidity index (CCI) was included [17].

\section{Statistical analysis}

The differences in the rates of general characteristics were analyzed using the chi-square test. The difference in the mean values of income between hearing-impaired and comparison participants for 5 years was compared using paired $t$-tests. A linear mixed model was used to analyze the interaction between repeatedly measured income levels according to time and hearing impairment and estimated value (EV) of repeated-measures data of income levels for hearing impairment. Age, sex, region of residence, hearing impairment, and time of measurement were used as the independent variables and fixed effects. BMI, systolic blood pressure, diastolic blood pressure, fasting blood glucose, total cholesterol, smoking, alcohol consumption, and CCI scores were used as random effects. A first-order autoregressive model was selected as the repeated covariance type, considering the correlation of each participant's iteration. The statistical analysis model of the linear mixed model is as follows.

$$
Y_{i}=X_{i i} \beta_{1}+\cdots+X_{i p} \beta_{p}+Z_{i i} \mathrm{u}_{i}+\cdots+Z_{i q} \mathrm{u}_{q}+e_{i} \text {, for all } i=1, \cdots, n,
$$

where $Y=\left(Y_{1}, \cdots, Y_{n}\right)^{\prime}, \mathrm{X}$ is the $n \times p$ matrix of covariates with fixed effects $\beta=\left(\beta_{1}, \cdots, \beta_{p}\right)^{\prime}, \mathrm{Z}$ is the $n \times q$ matrix of covariates with random effects $\mathrm{u}=\left(u_{1}, \cdots, u_{q}\right)^{\prime} \sim \mathrm{N}\left(0, \tau I_{q}\right)$, and the residual error vector $e^{=}\left(e_{1}, \cdots, e_{n}\right)^{\prime} \sim \mathrm{N}\left(0, \tau I_{n}\right)$.

Two-tailed analyses were conducted using SAS ver. 9.4 (SAS Institute Inc., Cary, NC, USA). A $P<0.05$ was considered statistically significant.

\section{RESULTS}

The distribution of the initial income level was matched between the hearing-impaired and comparison groups $(P=1.000)$ (Table 1$)$. The income level distribution of this cohort $(n=514,866)$ is described in Supplementary Table 1. The income levels increased over the course of follow-up in both the hearing-impaired and comparison groups (Table 2 and Supplementary Table 2). In the hearing-impaired group, the income levels 4 and 5 years postenrollment were significantly higher than the initial income level (each $P<0.001$ ), while the income levels $1-3$ years post-enrollment were not (each $P>0.05$ ). In the comparison group, the income levels from 1 year through 5 years post-enrollment were significantly higher than the initial income level (each $P<0.001$ ). The interaction effect between time and hearing impairment for income level was significant $(P=0.021)$. The $\mathrm{EV}$ of income level for the hearing-impaired group was estimated to be $-0.016(P=$ 0.721 )

The interaction effect between time and hearing impairment for 
Table 1. General characteristics of participants

\begin{tabular}{|c|c|c|c|}
\hline Characteristics & Hearing impairment & Control & $P$-value \\
\hline Age (yr) & & & 1.000 \\
\hline $40-44$ & $283(4.8)$ & $1,132(4.8)$ & \\
\hline $45-49$ & $394(6.7)$ & $1,576(6.7)$ & \\
\hline $50-54$ & $547(9.3)$ & $2,188(9.3)$ & \\
\hline $55-59$ & $770(13.2)$ & $3,080(13.2)$ & \\
\hline $60-64$ & $917(15.7)$ & $3,668(15.7)$ & \\
\hline $65-69$ & $994(17.0)$ & $3,976(17.0)$ & \\
\hline $70-74$ & $931(15.9)$ & $3,724(15.9)$ & \\
\hline $75-79$ & $695(11.9)$ & $2,780(11.9)$ & \\
\hline $80-84$ & $278(4.8)$ & $1,112(4.8)$ & \\
\hline$\geq 85$ & $48(0.8)$ & $192(0.8)$ & \\
\hline Sex & & & 1.000 \\
\hline Male & $3,627(61.9)$ & $14,508(61.9)$ & \\
\hline Female & $2,230(38.1)$ & 8,920 (38.1) & \\
\hline Initial income & & & 1.000 \\
\hline 0 (Lowest) & $157(2.7)$ & $628(2.7)$ & \\
\hline 1 & $628(10.7)$ & $2,512(10.7)$ & \\
\hline 2 & $403(6.9)$ & $1,612(6.9)$ & \\
\hline 3 & 479 (8.2) & $1,916(8.2)$ & \\
\hline 4 & $490(8.4)$ & $1,960(8.4)$ & \\
\hline 5 & $470(8.0)$ & $1,880(8.0)$ & \\
\hline 6 & $494(8.4)$ & $1,976(8.4)$ & \\
\hline 7 & $477(8.1)$ & $1,908(8.1)$ & \\
\hline 8 & $567(9.7)$ & $2,268(9.7)$ & \\
\hline 9 & $802(13.7)$ & $3,208(13.7)$ & \\
\hline 10 (Highest) & $890(15.2)$ & $3,560(15.2)$ & \\
\hline Region of residence & & & 1.000 \\
\hline Urban & $2,380(40.6)$ & $9,520(40.6)$ & \\
\hline Rural & $3,477(59.4)$ & $13,908(59.4)$ & \\
\hline Obesitya) & & & 0.569 \\
\hline Underweight & 208 (3.6) & $841(3.6)$ & \\
\hline Normal & $2,183(37.3)$ & $8,577(36.6)$ & \\
\hline Overweight & $1,513(25.8)$ & $6,295(26.9)$ & \\
\hline Obese I & $1,814(31.0)$ & $7,142(30.5)$ & \\
\hline Obese II & $139(2.4)$ & $573(2.5)$ & \\
\hline Smoking status & & & $<0.001^{\text {b) }}$ \\
\hline Nonsmoker & $4,216(72.0)$ & $16,156(69.0)$ & \\
\hline Past smoker & $530(9.1)$ & 2,312 (9.9) & \\
\hline Current smoker & $1,111(19.0)$ & $4,960(21.2)$ & \\
\hline Alcohol consumption & & & $<0.001^{\mathrm{b})}$ \\
\hline$<1$ time a week & $4,406(75.2)$ & $16,983(72.5)$ & \\
\hline$\geq 1$ time a week & $1,451(24.8)$ & $6,445(27.5)$ & \\
\hline Systolic blood pressure (mmHg) & & & 0.731 \\
\hline$<120$ & $1,352(23.1)$ & $5,419(23.1)$ & \\
\hline $120-139$ & 2,666 (20.2) & $10,541(79.8)$ & \\
\hline$\geq 140$ & $1,839(31.4)$ & 7,468 (31.9) & \\
\hline Diastolic blood pressure $(\mathrm{mmHg})$ & & & 0.060 \\
\hline$<80$ & $2,263(38.6)$ & $9,021(38.5)$ & \\
\hline $80-89$ & $2,181(37.2)$ & $8,430(36.0)$ & \\
\hline$\geq 90$ & $1,413(24.1)$ & $5,977(25.5)$ & \\
\hline Fasting blood glucose (mg/dL) & & & 0.208 \\
\hline$<100$ & $3,706(63.3)$ & $14,614(62.4)$ & \\
\hline $100-125$ & $1,593(27.2)$ & $6,410(27.4)$ & \\
\hline$\geq 126$ & $558(9.5)$ & $2,404(10.3)$ & \\
\hline
\end{tabular}


Table 1. Continued

\begin{tabular}{|c|c|c|c|}
\hline Characteristics & Hearing impairment & Control & $P$-value \\
\hline Total cholesterol (mg/dL) & & & $0.012^{b)}$ \\
\hline$<200$ & $3,247(55.4)$ & $12,484(53.3)$ & \\
\hline 200-239 & $1,859(31.7)$ & $7,749(33.1)$ & \\
\hline$\geq 240$ & $751(12.8)$ & $3,195(13.6)$ & \\
\hline $\mathrm{CCl}$ score & & & $<0.001^{\text {b) }}$ \\
\hline 0 & $3,182(54.3)$ & $13,498(57.6)$ & \\
\hline 1 & $1,124(19.2)$ & $3,809(16.3)$ & \\
\hline 2 & $694(11.9)$ & $2,449(10.5)$ & \\
\hline 3 & $386(6.6)$ & $1,447(6.2)$ & \\
\hline$\geq 4$ & $471(8.0)$ & $2,225(9.5)$ & \\
\hline
\end{tabular}

Values are presented as number (\%).

$\mathrm{CCl}$, Charlson comorbidity index.

a) Obesity (body mass index, $\mathrm{kg} / \mathrm{m}^{2}$ ) was categorized as $<18.5$ (underweight), $\geq 18.5$ to $<23$ (normal), $\geq 23$ to $<25$ (overweight), $\geq 25$ to $<30$ (obese I), and $\geq 30$ (obese II). ${ }^{\text {b) }}$ Chi-square test; significance at $P<0.05$.

income level was significant in the subgroup of men $<65$ years $(P<0.001)$ (Table 2). In this subgroup, the income level of the hearing-impaired group decreased at 1 year post-enrollment $(P=0.036)$ and was not significantly different from the initial level across $2-5$ years post-enrollment, while the income level increased from the initial level across $1-5$ years post-enrollment (each $P<0.001$ ) in the comparison group. Over the course of time, the decreased 1-year post-enrollment income in the hearing-impaired group recovered. In contrast, the comparison group demonstrated a higher income level from 1 year through 5 years postenrollment compared to the initial income level (each $P<0.001$ ). The EV of income level for hearing impairment was estimated to be -0.015 in this subgroup $(P=0.836)$. The $\geq 65$-year-old men, $<65$-year-old women, and $\geq 65$-year-old men did not show a significant interaction between time and hearing impairment.

According to the degree of hearing impairment, the profound hearing-impaired group demonstrated a significant interaction between time and hearing impairment for income level $(P=0.020)$ (Table 3). The profound hearing-impaired group also demonstrated higher income levels at 4 and 5 years post-enrollment than the initial income level $(P=0.028$ and $P=0.014$, respectively). The $\mathrm{EV}$ of income level for hearing impairment was estimated to be -0.026 in this subgroup $(P=0.809)$.

\section{DISCUSSION}

The increase in income level was lower in the hearing-impaired group than in the comparison group. As a result, the economic gap between the hearing-impaired and comparison populations increased. Although both the hearing-impaired and comparison groups demonstrated increasing income levels over time, the difference reached statistical significance after 4 years in the hearing-impaired group and after 1 year in the comparison group. The interaction of time and hearing impairment for income level was proven in a linear mixed model. This is consistent with profound hearing loss. Moreover, $<65$-year-old men showed a decrease in income level after hearing impairment. To our knowledge, few previous studies have investigated changes in income after hearing impairment with appropriate comparisons.

A few previous studies have also reported economic inequalities in hearing-impaired populations. In the United States adult population, hearing impairment was related to unemployment (OR, 2.2; 95\% CI, 1.4-3.4) and lower wages (net difference, $\$ 7,791 ; P<0.001)[18]$. In Chinese adults, hearing impairment was associated with blue-collar workers and unemployment (OR, 1.2; 95\% CI, 1.0-1.3 and OR, 1.2; 95\% CI, 1.0-1.4, respectively) [19]. A recent meta-analysis demonstrated a relationship between hearing impairment and unemployment [20]. Unlike previous studies, this study documented the progression of hearing impairment-associated income inequality over time, through the use of longitudinal measurements after matching the initial income level of the hearing-impaired and comparison participants.

A number of difficulties in hearing-impaired populations, including communication, working performance, comorbidities, and social discrimination, could mediate the lower income in the hearing-impaired population than in the comparison population. Working performance could be affected by communication difficulties in hearing-impaired persons. Hearing impairment was related to reduced work performance for long hours, although the negative impact of hearing impairment on work performance was compensated over time [21]. Hearing-impaired adults showed gaps in information processing, techniques, and services to maintain optimal productivity, which resulted in inferior abilities in multidimensional tasks and coordination in the workplace [22]. In addition, relative to non-hearing-impaired adults, adults with hearing impairment demonstrated more recovery time after work and more sick leave [23,24]. Thus, it is suggested that assistive devices to support auditory perception 


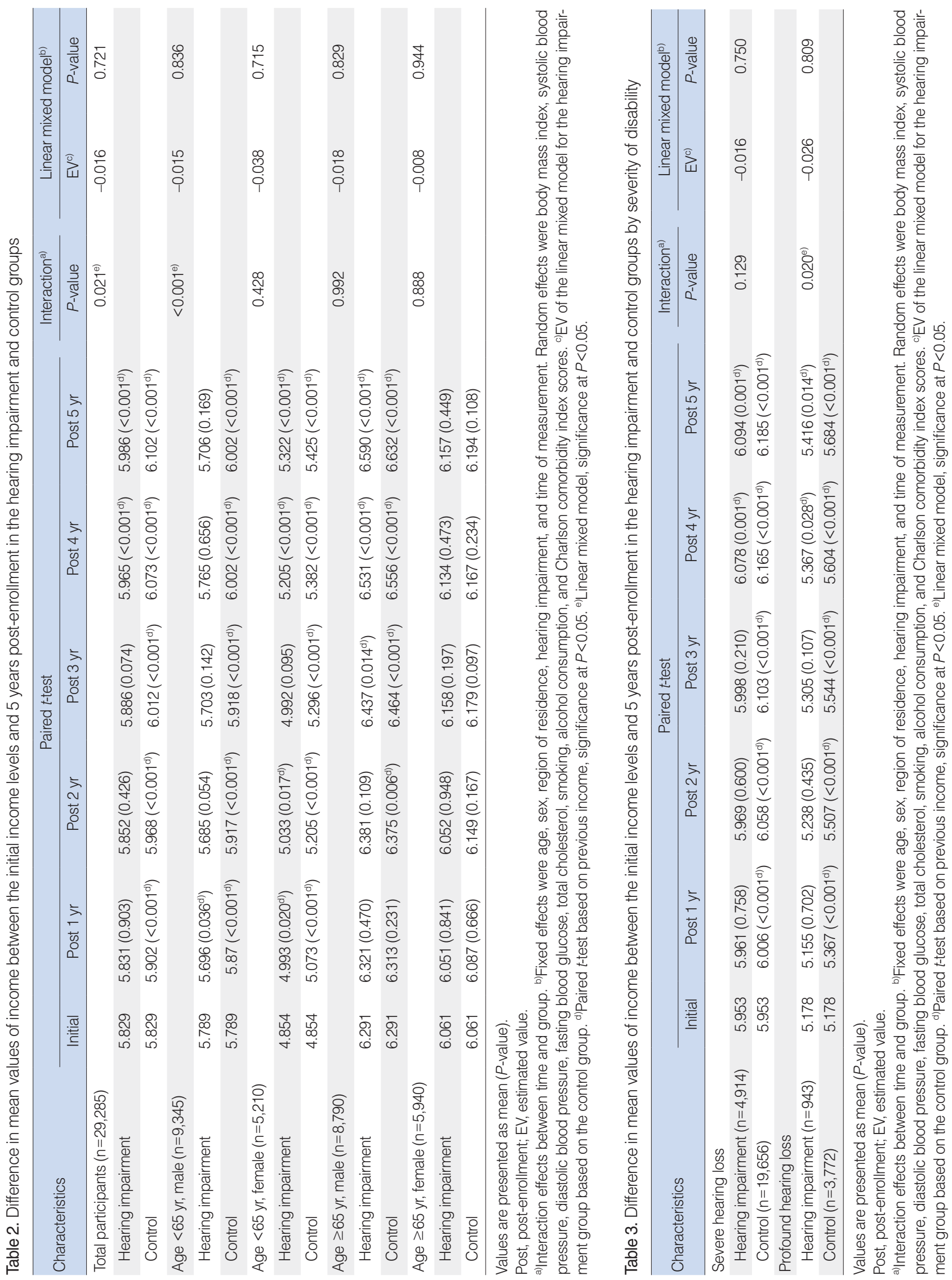


and communication need to be implemented for hearing-impaired persons in the workplace [25].

The higher disease burden in hearing-impaired persons may impact income levels. Hearing impairment was found to be associated with hospitalization for any reason, more than 10 days of self-reported poor physical health, and more than 10 days of self-reported poor mental health in elderly individuals [26]. Because multiple comorbidities have been reported as factors associated with hearing impairment [27], participants with disabilities were excluded from the present study. The higher rate of comorbidities in hearing-impaired persons could induce both higher healthcare costs and a lower capability to work, thereby resulting in lower income and an increasing gap in economic levels. In addition, social discrimination toward hearing-impaired persons could limit promotion in their working positions.

The lower income change in the hearing-impaired group was consistent in the subgroup of $<65$-year-old men in the present study. This younger age group is expected to be economically more active than the older age group. Therefore, the impacts of the differences on employment status and working performance on income levels might be especially strong in this age group. In contrast, after retirement (i.e., in the $\geq 65$-year-old population), employment status might have little effect on the income level in both the hearing-impaired and comparison groups. For women, employment status and wage differences might be lower than those of men because more men than women are in the workplace in Korea. It is estimated that in $2014, \geq 20$-year-old Korean women expended approximately 2 hours and 44 minutes on income labor and 3 hours and 29 minutes on household chores, while men expended approximately 4 hours and 45 minutes on income labor and 47 minutes on household chores [28]. In the present study, the value of household chores was not reflected as income.

Individuals with profound hearing impairment showed lower income changes than the comparison group. A higher degree of hearing impairment might contribute to more difficulties in social communication and a higher risk of other comorbidities than in those with a lower degree of hearing impairment. For instance, the association of dementia with hearing impairment was more prominent in individuals with profound hearing impairment than in those with severe hearing impairment [13]. The association of profound hearing impairment with mortality was 4.22 times (95\% CI, 3.52-5.05) higher than that of the comparison group and showed higher odds than the severe hearing-impaired group (adjusted OR, 4.07; 95\% CI, 3.71-4.46) [14].

All Koreans are registered in the NHIS without exception, and their health insurance claims and health check-up data can be traced [29]. We matched the comparison group in terms of both demographic and socioeconomic factors. Medical histories were adjusted using the $\mathrm{CCI}$ score. In addition, lifestyle factors, body measurements, and laboratory data were considered in the analysis of the association between income changes and hearing im- pairment. Income level was based on NHIS data, which guarantee the accuracy of income levels. Hearing impairment was classified based on registered persons with hearing impairment in the NHIS.

However, the duration of hearing impairment was heterogeneous among the hearing-impaired population. For the degree of hearing impairment, we included only participants with severe or higher degrees of hearing impairment. In addition, this study could not account for the effect of hearing rehabilitation using hearing aids or cochlear implants [30]. The prevalence of regular hearing aid use is approximately $12.6 \%$ in the $\geq 40$-yearold population of Korea [31]. Information on income levels in this study was based on the NHIS-HEALS data, which include all Koreans $\geq 40$ years old. All $\geq 40$-year-old Koreans undergo annual health check-ups for free. Because the health check-up data were not available for the $<40$-year-old population, only the $\geq 40$-year-old population could be included in the present study. In addition, employment status could not be assessed in the cohort data. Economic levels were estimated based on income levels because other types of property, such as real estate and domestic chores, could not be counted in the present study. Thus, the follow-up periods and differences in income levels were restricted. A further study with a younger population and longer follow-up could provide improved information on the associations between hearing impairment and income changes. Last, although comorbidities were adjusted using the CCI score, several possible confounders, such as educational status, overall socioeconomic status, parental economic level, and other acquired or congenital problems, could not be accounted for in this study.

In conclusion, hearing impairment was associated with a lower increase in income in the $\geq 40$-year-old Korean population. As time progressed, this gap in economic inequality between the hearing-impaired and comparison groups increased. The relationship of hearing impairment with income change was especially prominent among $<65$-year-old men and those with profound hearing loss.

\section{CONFLICT OF INTEREST}

No potential conflict of interest relevant to this article was reported.

\section{ACKNOWLEDGMENTS}

This work was supported by a research grant (NRF-2018-R1D1A1A02085328, 2021-R1C1C100498611, and 2020R1A2C4002594) from the National Research Foundation (NRF) of Korea. 


\section{ORCID}

So Young Kim

Chanyang Min

Dae Myoung Yoo

Jiwon Chang

Hyo-Jeong Lee

Bumjung Park

Hyo Geun Choi https://orcid.org/0000-0002-7361-4930

https://orcid.org/0000-0002-0629-9299

https://orcid.org/0000-0003-2511-5536

https://orcid.org/0000-0003-1660-1831

https://orcid.org/0000-0003-2258-0803

https://orcid.org/0000-0001-6074-6339

https://orcid.org/0000-0003-1655-9549

\section{AUTHOR CONTRIBUTIONS}

Conceptualization: HGC. Data curation: CM, DMY, HGC. Formal analysis: CM, DMY. Funding acquisition: HGC, SYK. Methodology: CM, DMY, HGC. Project administration: HGC. Visualization: HGC. Writing-original draft: SYK. Writing-review \& editing: all authors.

\section{SUPPLEMENTARY MATERIALS}

Supplementary materials can be found via https://doi.org/10. 21053/ceo.2021.00325.

\section{REFERENCES}

1. Kontis V, Cobb LK, Mathers CD, Frieden TR, Ezzati M, Danaei G. Three public health interventions could save 94 million lives in 25 years. Circulation. 2019 Aug;140(9):715-25.

2. GBD 2015 disease and injury incidence and prevalence collaborators. Global, regional, and national incidence, prevalence, and years lived with disability for 310 diseases and injuries, 1990-2015: a systematic analysis for the Global Burden of Disease Study 2015. Lancet. 2016 Oct;388(10053):1545-602.

3. Goman AM, Lin FR. Prevalence of hearing loss by severity in the united states. Am J Public Health. 2016 Oct;106(10):1820-2.

4. Sharma RK, Lalwani AK, Golub JS. Prevalence and severity of hearing loss in the older old population. JAMA Otolaryngol Head Neck Surg. 2020 Aug;146(8):762-3.

5. Exeter DJ, Wu B, Lee AC, Searchfield GD. The projected burden of hearing loss in New Zealand (2011-2061) and the implications for the hearing health workforce. N Z Med J. 2015 Aug;128(1419): $12-21$.

6. GBD 2016 disease and injury incidence and prevalence collaborators. Global, regional, and national incidence, prevalence, and years lived with disability for 328 diseases and injuries for 195 countries, 1990-2016: a systematic analysis for the Global Burden of Disease Study 2016. Lancet. 2017 Sep;390(10100):1211-59.

7. Shukla A, Harper M, Pedersen E, Goman A, Suen JJ, Price C, et al. Hearing loss, loneliness, and social isolation: a systematic review. Otolaryngol Head Neck Surg. 2020 May;162(5):622-33.

8. Ramsey T, Svider PF, Folbe AJ. Health burden and socioeconomic disparities from hearing loss: a global perspective. Otol Neurotol. 2018 Jan;39(1):12-6.

9. Emmett SD, Francis HW. The socioeconomic impact of hearing loss in U.S. adults. Otol Neurotol. 2015 Mar;36(3):545-50.

10. Lee JS, Choi HG, Jang JH, Sim S, Hong SK, Lee HJ, et al. Analysis of predisposing factors for hearing loss in adults. J Korean Med Sci. 2015 Aug;30(8):1175-82.

11. Jones DD. Relative earnings of deaf and hard-of-hearing individuals. J Deaf Stud Deaf Educ. 2004 Fall;9(4):459-61.

12. Kim SY, Min C, Oh DJ, Choi HG.Tobacco smoking and alcohol consumption are related to benign parotid tumor: a nested case-control study using a national health screening cohort. Clin Exp Otorhinolaryngol. 2019 Nov;12(4):412-9.

13. Kim SY, Lim JS, Kong IG, Choi HG. Hearing impairment and the risk of neurodegenerative dementia: a longitudinal follow-up study using a national sample cohort. Sci Rep. 2018 Oct;8(1):15266.

14. Kim SY, Min C, Kim HJ, Lee CH, Sim S, Park B, et al. Mortality and cause of death in hearing loss participants: a longitudinal follow-up study using a national sample cohort. Otol Neurotol. 2020 Jan;41 (1):25-32.

15. National Health Insurance Service. National medical examination sample cohort (NHIS-NMES) user manual [Internet]. Wonju: National Health Insurance Service; 2017 [cited 2021 Apr 1]. Available from: https://nhiss.nhis.or.kr/bd/ab/bdaba006cv.do.

16. Kim SY, Oh DJ, Park B, Choi HG. Bell's palsy and obesity, alcohol consumption and smoking: a nested case-control study using a national health screening cohort. Sci Rep. 2020 Mar;10(1):4248.

17. Quan H, Li B, Couris CM, Fushimi K, Graham P, Hider P, et al. Updating and validating the Charlson comorbidity index and score for risk adjustment in hospital discharge abstracts using data from 6 countries. Am J Epidemiol. 2011 Mar;173(6):676-82.

18. Jung D, Bhattacharyya N.Association of hearing loss with decreased employment and income among adults in the United States. Ann Otol Rhinol Laryngol. 2012 Dec;121(12):771-5.

19. He P, Luo Y, Hu X, Gong R, Wen X, Zheng X. Association of socioeconomic status with hearing loss in Chinese working-aged adults: a population-based study. PLoS One. 2018 Mar;13(3):e0195227.

20. Shan A, Ting JS, Price C, Goman AM, Willink A, Reed NS, et al. Hearing loss and employment: a systematic review of the association between hearing loss and employment among adults. J Laryngol Otol. 2020 May;134(5):387-97.

21. Wagner-Hartl V, Grossi NR, Kallus KW. Impact of age and hearing impairment on work performance during long working hours. Int J Environ Res Public Health. 2018 Jan;15(1):98.

22. Jennings MB, Shaw L. Impact of hearing loss in the workplace: raising questions about partnerships with professionals. Work. 2008;30 (3):289-95.

23. Nachtegaal J, Kuik DJ, Anema JR, Goverts ST, Festen JM, Kramer SE. Hearing status, need for recovery after work, and psychosocial work characteristics: results from an internet-based national survey on hearing. Int J Audiol. 2009;48(10):684-91.

24. Kramer SE, Kapteyn TS, Houtgast T. Occupational performance: comparing normally-hearing and hearing-impaired employees using the Amsterdam Checklist for Hearing and Work. Int J Audiol. 2006 Sep;45(9):503-12.

25. Jennings MB, Shaw L, Hodgins H, Kuchar DA, Bataghva LP. Evaluating auditory perception and communication demands required to carry out work tasks and complimentary hearing resources and skills for older workers with hearing loss. Work. 2010;35(1):101-13.

26. Genther DJ, Frick KD, Chen D, Betz J, Lin FR. Association of hearing loss with hospitalization and burden of disease in older adults. JAMA. 2013 Jun;309(22):2322-4.

27. Besser J, Stropahl M, Urry E, Launer S. Comorbidities of hearing loss and the implications of multimorbidity for audiological care. Hear Res. 2018 Nov;369:3-14.

28. Thomas JP, Loke YK, Alexandre L. Efficacy and safety profile of statins in patients with cancer: a systematic review of randomised 
controlled trials. Eur J Clin Pharmacol. 2020 Dec;76(12):1639-51.

29. Lee J, Lee JS, Park SH, Shin SA, Kim K. Cohort profile: the national health insurance service-national sample cohort (NHIS-NSC), South Korea. Int J Epidemiol. 2017 Apr;46(2):e15.

30. Lee HJ, Lee JM, Na G, Moon YM, Lee C, Jung J.Which patients with a unilateral hearing aid for symmetric sensorineural hearing loss have auditory deprivation? Clin Exp Otorhinolaryngol. 2020 Feb;13(1): 23-8.

31. Moon IJ, Baek SY, Cho YS. Hearing aid use and associated factors in South Korea. Medicine (Baltimore). 2015 Oct;94(42):e1580. 